\title{
PRODUTOR FAMILIAR X AGRONEGÓCIO CANAVIEIRO: IMPACTOS DO CULTIVO DA CANA NA PRODUÇÃO DO BICHO DA SEDA EM MIRANTE DO PARANAPANEMA
}

\author{
Alba Regina Azevedo Arana ${ }^{1}$ \\ Maíra Rodrigues Uliana ${ }^{2}$ \\ Cintia Ramos Lopes Evangelista ${ }^{3}$
}

Resumo: O objetivo deste artigo é apresentar os desafios do produtor rural familiar hoje especialmente em regiões dominadas pelo agronegócio canavieiro. O trabalho traz as consequências ambientais do cultivo da cana na região do Pontal do Paranapanema, discutindo a prática da pulverização aérea nos canaviais, utilizadas pelas agroindústrias. Foi realizado o trabalho de campo junto aos produtores familiares de "São Bento III" em Mirante do Paranapanema, de maio a junho de 2016, a coleta de dados se deu através de questionários e entrevistas (relatos orais). A pesquisa de campo possibilitou notar que a chegada das unidades canavieiras para o Pontal do Paranapanema também tem trazido uma série de problemas para cidades/municípios da região e para a população em geral. Entre os quais, podem ser mencionados os impactos na saúde pública dos municípios, efeitos no meio ambiente em especial destacamos a morte das amoreiras no entorno do cultivo da cana e por consequência do cultivo do bicho da seda.

Palavras-chave: Cana-de-açúcar. Impactos. Pulverização aérea. Bicho-da-seda. Pontal.

\section{FAMILY PRODUCER $X$ SUGARCANE AGRIBUSINESS: IMPACTS OF SUGARCANE CULTIVATION ON SILKWORM PRODUCTION IN MIRANTE DO PARANAPANEMA-SP}

Abstract: The objective of this article is to present the challenges of family farmers today especially in regions dominated by sugar cane agribusiness. The aim of this paper is to present the environmental consequences of sugarcane cultivation in Pontal do Paranapanema, discussing the practice of aerial spraying on the cane fields by agribusinesses. It was conducted field work with rural resettlers of "São Bento III" in Mirante do Paranapanema, on May/June 2014, the data collection was carried out through questionnaires and interviews (oral reports). The field research has enabled to note that the arrival of sugarcane units in Pontal do Paranapanema has also brought a number of problems for close cities/municipalities and population. Among these issues can be mentioned the impacts on public health in municipalities, effects on the environment emphasizing the death of mulberry trees on surrounding sugarcane cultivation and, consequently, of silkworm cultivation.

Keywords: Sugar cane. Impacts. Aerial spraying. Silkworm. Pontal.

\footnotetext{
1 Universidade do Oeste Paulista- Unoeste, Programa de Pós graduação em Meio Ambiente e Desenvolvimento Regional da Unoeste, Presidente Prudente- SP, Brasil, albal@unoestel.br http://orcid.org/0000-0001-8995-4449

2 Universidade do Oeste Paulista - Unoeste, Programa de Pós graduação em Meio Ambiente e Desenvolvimento Regional da Unoeste, Presidente Prudente- SP, Brasil, maira@unoeste.br https://orcid.org/0000-0002-2794-0217

${ }^{3}$ Centro Universitário Toledo Prudente, Curso de Administração, Presidente Prudente-SP, Brasil, cintiarlevangelista@hotmail.com, https://orcid.org/0000-0002-6659-410X
} 


\section{PRODUCTOR FAMILIAR X AGRONEGOCIO CAÑA: IMPACTOS DEL CULTIVO DE LA CAÑA EN LA PRODUCCIÓN DEL BICHO DE LA SEDA EN MIRANTE DEL PARANAPANEMA-SP}

Resumen: El objetivo de este artículo es presentar los desafíos del productor rural familiar hoy especialmente en regiones dominadas por el agronegocio cañero. El trabajo trae las consecuencias ambientales del cultivo de la caña en la región del Pontal do Paranapanema, discutiendo la práctica de la pulverización aérea en los cañaverales, utilizadas por las agroindustrias. Se realizó el trabajo de campo junto a los productores familiares de "São Bento III" en Mirante del Paranapanema, de mayo a junio de 2016, la recolección de datos se dio a través de cuestionarios y entrevistas (relatos orales). La investigación de campo posibilitó notar que la llegada de las unidades cañaverales para el Pontal do Paranapanema también ha traído una serie de problemas para ciudades / municipios de la región y para la población en general. Entre los cuales, pueden mencionarse los impactos en la salud pública de los municipios, efectos en el medio ambiente en especial destacamos la muerte de las moreras en el entorno del cultivo de la caña y como consecuencia del cultivo del bicho de la seda.

Palabras clave: Caña de azúcar. Impactos. Pulverización aérea. Gusano de seda. Pontal.

\section{Introdução}

O Brasil é mundialmente reconhecido como líder em tecnologia, produção e eficiência na fabricação de etanol a partir da cana-de-açúcar, contando com uma estrutura produtiva consolidada e com décadas de desenvolvimento tecnológico. Hoje, o País é responsável por $45 \%$ da produção mundial de etanol combustível, que é obtido a partir da cana-de-açúcar cultivada em praticamente todas as regiões do País, e processada através de uma rede de mais de 400 usinas e destilarias, denominado de agronegócio canavieiro.

Para atender a esta conjuntura, que aponta para a necessidade de aumento da produção de álcool e de açúcar, houve uma retomada de investimentos, tanto na parte agrícola, quanto na parte industrial, o que resultou em um aumento significativo na área ocupada pela cultura, que saltou de 4,8 para 9,4 milhões de hectares, entre 2000 e 2009.

Desta forma, segundo os dados da UNICADATA (2017), o consumo total de etanol quase triplicou no país entre 2000 e 2015, passando de 10,3 para 28,7 bilhões de litros. Em relação ao açúcar, os dados do MAPA (2015) mostram que o consumo interno se manteve estável nos últimos anos, variando em torno de 10 a 13 milhões de toneladas. Entre as safras 2000/2001 e 2015/2016, a produção de 
açúcar saltou de 16,1 para 33,9 mil toneladas e a de etanol passou de 10,5 para 30,3 mil m3 (UNICADATA, 2017)

Em termos de exportações, o etanol teve crescimento tímido entre 2000 e 2008 (de 229 milhões para 5,1 bilhões de litros) e decrescimento entre 2009 e 2015 (3,3 para 1,8 bilhões de litros), ao contrário do que ocorreu com o açúcar, cujo comércio teve um crescimento de $269 \%$ entre 2000 e 2015, ou seja, de 6,5 para 24 milhões de toneladas exportadas (MDIC, 2017).

Contudo, apesar do aumentou da produção sucroalcooleira significar uma atividade muito lucrativa às empresas envolvidas nesta agroindústria existem alguns questionamentos relacionados às consequências a serem discutidas, tais como: a competição por alimentos, a segurança hídrica, a indução ao desmatamento pela expansão da fronteira agrícola, o uso de agrotóxicos em larga escala, a vulnerabilidade da agricultura às mudanças climáticas, os resíduos e efluentes gerados nas agroindústrias processadoras, entre outros (GONÇALVES; FERRAZ; SZMRECSÁNYI, 2008).

O crescimento vertiginoso do agronegócio canavieiro no Brasil e em particular no Estado de São Paulo, aumentou consideravelmente os potenciais poluidores das usinas e destilarias, obrigando os órgãos de controle e preservação do meio ambiente a intensificarem a fiscalização da disposição dos resíduos produzidos na produção do açúcar e do álcool.

O objetivo deste artigo é apresentar as consequências ambientais do agronegócio canavieiro na região do Pontal do Paranapanema, discutindo a prática da pulverização aérea nos canaviais, utilizadas pelas agroindústrias. Muitos são os prejuízos causados aos produtores do bicho-da-seda na região que atuam na produção da sericicultura, em especial no assentamento São Bento em Mirante do Paranapanema.

Desta forma, procura-se questionar: Qual o impacto social e ambiental do agronegócio canavieiro no Município do Mirante do Paranapanema? Quais as condições socioeconômicas dos produtores do bicho da seda neste município? As atividades produtivas nestes assentamentos são realizadas de forma eficiente? 0 que se quer provar é que a produção do bicho da seda, cultura tradicional destes produtores, foi impactada negativamente pelo cultivo da cana de açúcar e que muitos produtores abandonaram a atividade em razão dos prejuízos obtidos.

O artigo foi estruturado em quatro seções. Primeiramente, são apresentados os procedimentos metodológicos da pesquisa. Posteriormente, foi feita a descrição 
do objeto de estudo, o assentamento São Bento em Mirante do Paranapanema. No item seguinte, as análises da pesquisa de campo e os resultados obtidos, enquanto que no último item foram feitas as considerações finais.

\section{Metodologia}

O recorte espacial do estudo compreende a área denominada de Pontal do Paranapanema, Oeste Paulista, em especial o município de Mirante do Paranapanema-SP. Esta região se destaca pela quantidade de produtores agrícolas assentados no estado. A construção teórico-metodológica da pesquisa trilhou o caminho da investigação qualitativa, alicerçada por uma revisão bibliográfica.

Operacionalmente, a pesquisa passou por três etapas metodológicas, uma primeira etapa na qual se realizou a revisão bibliográfica sobre o assunto em livros, artigos e revistas especializadas. $\mathrm{O}$ aprofundamento teórico se baseou nos trabalhos de Leite (1981); Hespanhol (1996); Silva (2005); Souza (2006); entre outros. Um segundo momento, realizou-se a pesquisa documental na qual se fez o levantamento de dados e informações secundárias sobre o tema em órgãos como Instituto de Terras do Estado de São Paulo (ITESP), CATI (Coordenadoria de Assistência Técnica Integral), INCRA (Instituto Nacional de Colonização e Reforma Agrária) e CESP (Companhia Energética do Estado de São Paulo) A finalidade era identificar e verificar os projetos, os relatórios e outros documentos que referissem direta ou indiretamente ao objeto de estudo.

E num terceiro momento foi realizado o trabalho de campo junto aos produtores agrícolas assentados de "São Bento III" em Mirante do Paranapanema, de maio a junho de 2014, a coleta de dados se deu através de questionários e entrevistas (relatos orais), com o uso de gravador, utilizadas como principais fontes de informação, possibilitando um entendimento da perspectiva dos assentados. Foram entrevistadas cerca de 20 famílias de reassentados, o objetivo era obter uma amostra qualitativa dos dados. O questionário se baseou em informações socioeconômica, escolaridade, modo de vida das famílias, produção agropecuária e renda. Na escolha para pesquisa de campo utilizou-se amostra aleatória por meio de carta topográfica do assentamento fornecida pela ITESP. O trabalho de campo visou verificar os impactos do plantio da cana-de-açúcar na produção do bicho da seda junto aos produtores agrícolas do assentamento "São Bento III", localizado na bacia hidrográfica do Ribeirão Santo Antônio em Mirante do Paranapanema-SP. 
Os depoimentos orais foram transcritos com base nas orientações metodológicas de Queiroz (1991). A fim de garantir a qualidade e riqueza das informações obtidas nos relatos, as entrevistas foram planejadas e orientadas por um roteiro de questões.

\section{O assentamento São Bento em Mirante do Paranapanema}

Segundo o DATALUTA (2013, p. 16), "o Município de Mirante do Paranapanema possui um número significativo de 35 assentamentos", representando 39\% (90) dos assentamentos do Pontal do Paranapanema, com uma área de 31.748,28 ha, sendo o assentamento São Bento um deles.

No processo de constituição do Assentamento São Bento, várias relações foram estabelecidas tendo contado com a participação de várias organizações, instituições e movimentos sociais. Lembra-se que esta região é uma das principais áreas de conflitos fundiários do país em que ocorre grande número de ocupação de terra; além disso, o Pontal é conhecido também por ser uma das regiões mais pobres do estado de São Paulo e por possuir milhares de hectares de terras improdutivas, devolutas e griladas por latifundiários, o que torna a concentração de terras bastante grande na região, impedindo assim o seu desenvolvimento (BORGES apud SOUZA, 2006, p.34):

[...] Depois de oito meses acampadas nas margens da rodovia, as famílias decidiram ocupar, em 23/03/1991, uma área de 2.872 ha da fazenda São Bento, localizada no município de Mirante do Paranapanema. Essa fazenda tinha ao todo 5.106 ha e estava sob o domínio de um famoso grileiro, exprefeito de Presidente Prudente, o Sr. Antônio Sandoval Neto. Além da fazenda São Bento, o ex-prefeito de Presidente Prudente também tinha em seu nome outras fazendas, como a Santo Antônio, a Alvorada e a Santo Emílio, as quais possuíam cada uma, uma extensão de cerca de 1.500 ha, que eram destinados à criação de gado. Sendo essas fazendas vizinhas da fazenda São Bento, e não havendo divisas para separar-Ihes, acabavam por virar uma única fazenda, a fazenda São Bento.

Esta situação, segundo levantamentos realizados, levou a uma "batalha" de invasões pelas famílias de sem terras e a retomada pelo Sr. Antônio da posse a fazenda São Bento, em cima de muitas lutas, mortes e danos que duraram alguns anos. A percepção dos assentados de que esta foi uma ocupação que entrou para a história do Pontal do Paranapanema e, quem sabe, para a história do país, no que tange à questão agrária. 
Os trabalhadores rurais organizados decidiram por ocupar essa fazenda porque, além dela ser a representante do poder do latifúndio na região, o governo federal já havia decretado que esta área deveria servir para fins de reforma agrária: "Com efeito, em 31/03/1987, o Presidente da República assinou o Decreto 94.161, declarando de interesse social para fins de reforma agrária, uma parte da fazenda São Bento, que corresponde a 2.872,50 há" (ALMEIDA, 1993 apud SOUZA, 2006, p. 35).

Em março de 1991, o MST promoveu a ocupação da fazenda São Bento, que tinha cerca de 5 mil hectares e se situava no $11^{\circ}$ perímetro (Mirante do Paranapanema). "Muitas idas e vindas marcaram esse processo, com ocupações, despejos sucessivos e violência [...]. Em 1992 a Fazenda São Bento voltou a ser ocupada muitas vezes" (FUNDAÇÃO ITESP, 2013, p. 139).

Devido à tensão que se criou na região, o governador do estado da época, Luís Antônio Fleury Filho, assinou um decreto em 21 de junho de 1991 em que requisitava 2.872 ha da fazenda São Bento para o assentamento das 247 famílias. Porém, por meio de uma liminar, o fazendeiro-grileiro conseguiu suspender 0 decreto. Mas, o Tribunal de Justiça do Estado de São Paulo destinou uma área de 10 ha da fazenda para as famílias montarem acampamento. Algumas famílias acamparam nesses 10 há. (SOUZA, 2006, p. 37).

As ocupações na fazenda São Bento configuram-se em um marco histórico, uma vez que coloca em evidência o movimento organizado pelos trabalhadores rurais sem-terra que exigia seus direitos frente ao Estado. $O$ assentamento na fazenda São Bento foi a segunda conquista do MST no Pontal do Paranapanema e significou a derrota de um dos maiores grileiros da região. Depois de quatro anos de negociações, em julho de 1994 o governo do Estado começou a realizar o assentamento provisório de 996 famílias na fazenda São Bento, tendo sido atribuída uma área de três hectares e meio para cada família. (SOUZA, 2006).

\section{Resultado e Discussão}

\section{Os impactos socioterritoriais da cana no Assentamento no São Bento}

São Bento é dividido em quatro grandes glebas, tendo sido formado o São Bento I, II, III e IV (figura 1). O número total de famílias chega a 182, somente no São Bento III são 44 famílias. O São Bento III é composto por 44 lotes que possuem o tamanho variável entre 16 e 20 ha. Em cada lote esta assentada uma família de 
acordo com legislação de uso e ocupação do solo para assentamentos rurais do Estado de São Paulo.

Figura 1-Localização do Assentamento São Bento III na Bacia Hidrográfica Ribeirão Santo Antônio

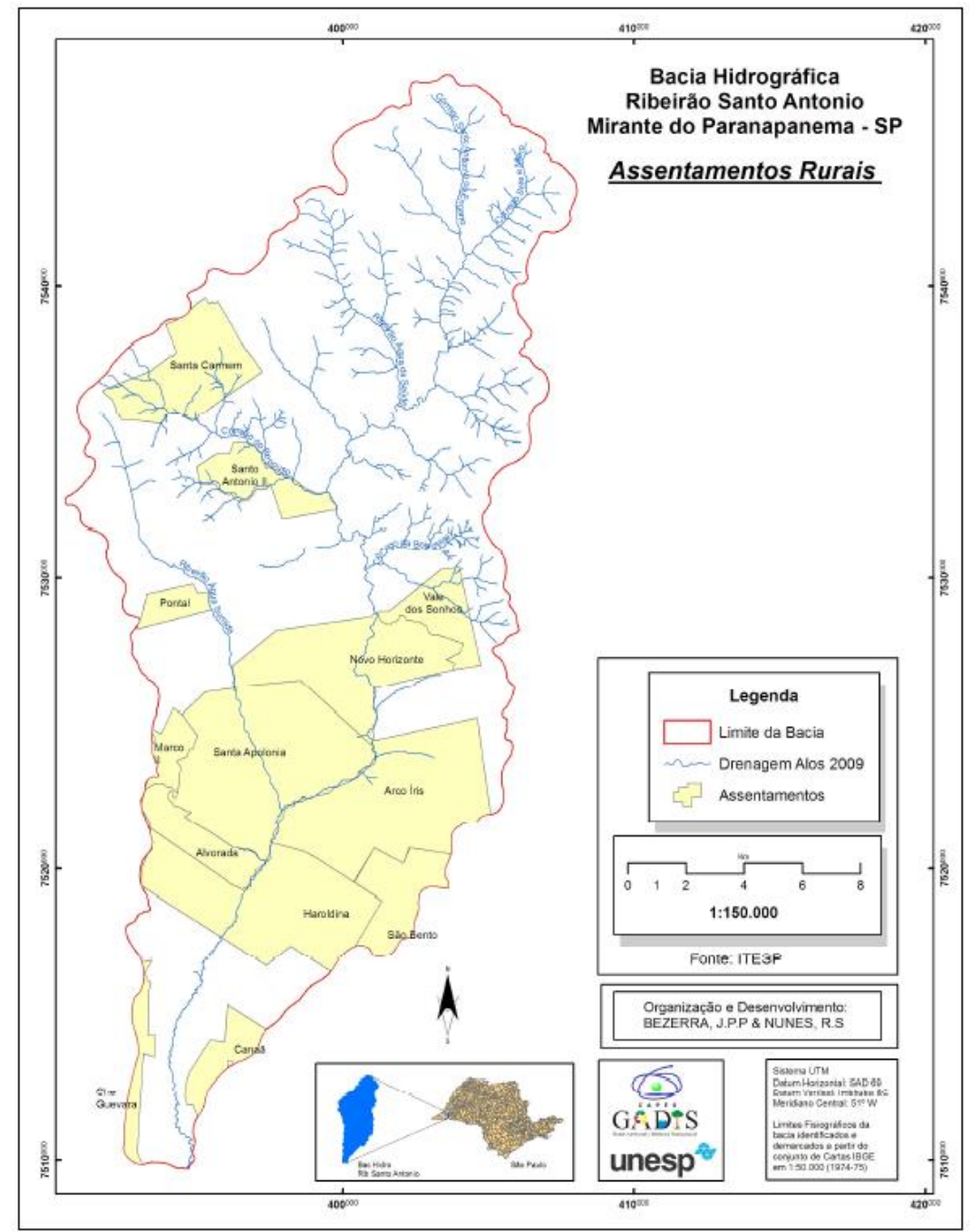

Fonte: Bezerra (2011).

A amostragem no assentamento se deu por probabilística aleatória simples por sorteio, desta forma, das 44 famílias 20 (55\%) famílias forma utilizadas para a realização do trabalho de campo através das entrevistas (figura 2). 


\section{Figura 2-Delineamento da área do Assentamento São Bento III}

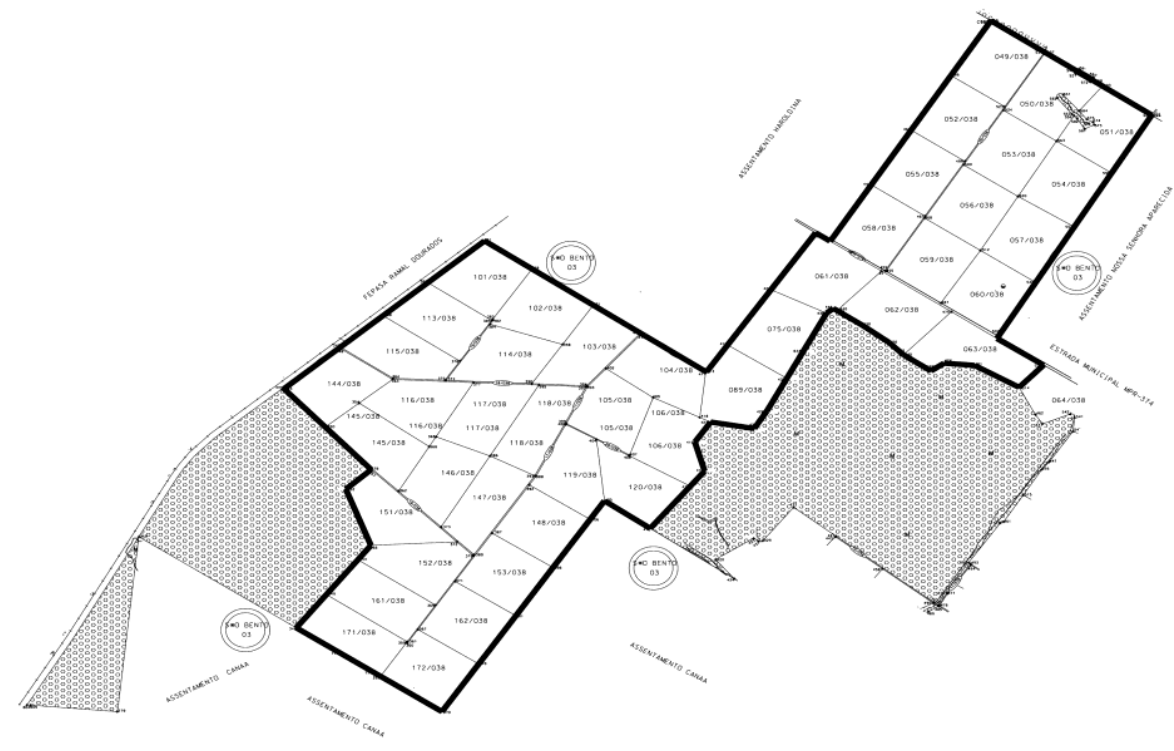

Fonte: Fundação ITESP (2014).

Para melhor esclarecimento e visualização da figura 3 demonstra a planta de composição dos 44 lotes do assentamento São Bento III. A área achurada na cor cinza demonstra a área de preservação ambiental.

O questionário aplicado aos produtores agrícolas foi o do tipo semiaberto onde se pretendeu traçar o seu perfil (numero de pessoas da família, nível de instrução, infraestrutura disponível, atividades desenvolvidas e etc.) e, também, realizado o mapeamento e levantamento de dados dos lotes sobre os impactos da cana na produção do bicho da seda. Em relação à obtenção da titularidade da posse da terra, 18 (90\%) produtores são do sexo feminino e 02 (10\%) são do sexo masculino.

Foi verificado que faixa etária dos produtores se concentra na idade entre 40 a 49 anos (30\%), sendo ainda que $25 \%$ dos produtores possuem entre 50 a 59 anos de idade e os produtores com idades entre 30 e 39 anos, 60-69 anos e 70 anos ou mais, corresponderam a $03(15 \%)$ do total de cada uma das faixas etárias.

Para a composição familiar levou-se em consideração o número de filhos que moram na residência instalada dentro do lote rural, tendo sido identificado que 06 (30\%) entrevistados não possuem filhos, sendo que na mesma ordem de produtores e de porcentagem possuem 01 filho, e, 06 (30\%) produtores possuem dois filhos. Apenas 01 (5\%) produtor possui três filhos e, também, apenas 01 (5\%) produtor possui mais de três filhos. 
Em relação ao nível de escolaridade, 14 (70\%) produtores estudaram até o nível fundamental e 06 (30\%) produtores possuem o nível médio de escolaridade. Apenas 01 (5\%) produtor está estudando o ensino médio atualmente e sua idade é de 48 anos.

Sobre o rendimento familiar, verificou-se que 05 (25\%) produtores não quiseram declarar seus ganhos mensais; 06 (30\%) produtores recebem até 1 salário mínimo que em 2014 estava no valor de $R \$ 724,00$ (setecentos e vinte e quatro reais); 02 (10\%) produtores recebem entre 01 a 02 salários e 06 (30\%) produtores tem recebimento mensal na ordem de 03 a 04 salários mínimos. Apenas 01 (5\%) produtor tem recebimento mensal entre 05 a 06 salários mínimos.

Para o uso da terra, foi verificado que do total da população amostrada, 14 (70\%) produtores possuem horta na propriedade onde, 05 (25\%) possuem horta com plantas medicinais. Todos os 20 (100\%) produtores possuem pomar com diversificação de frutas, onde as mais citadas foram manga, goiaba, acerola, amora, limão e mamão. O plantio da amora é utilizado para a sericicultura, contudo observou-se que todos os produtores entrevistados já abandonaram a atividade em razão da morte dos casulos.

Em relação a possuir animais de criação, 18 (90\%) produtores disseram possuir gado de leite; 18 (90\%) produtores criam galinhas e 13 (65\%) produtores criam outros tipos de animais como equinos, porcos e cabras para apoio na propriedade (equinos) e consumo próprio.

Dentro do prisma da atividade agropecuária, foi verificado junto aos produtores o nível de importância que assume para ele e sua família a produção agrícola e de animais, onde foi constatado que a atividade leiteira assume o primeiro lugar para todos os 18 (90\%) produtores que criam gado de leite; para 01 (05\%) produtor o eucalipto é sua principal fonte de renda e para outro 01 (05\%) produtor o arrendamento da terra para plantio de eucalipto sua principal fonte de renda. $O$ cultivo e manutenção de pomar ocupou o segundo lugar de atividade mais citada para 04 (20\%) produtores. Na sequência vieram a criação de peixes para 02 (10\%) produtores, dentre outras atividades identificadas que trazem renda ao produtor, está a criação do bicho da Seda.

Assim, em termos de sobrevivência familiar, muitos reassentados complementam sua renda familiar com trabalho assalariado na cidade. As dificuldades que os pequenos agricultores encontram são inúmeras como, a baixa fertilidade do solo ou falta de assistência técnica e financeira, levando a implicações 
na geração de renda. Assim a população rural não consegue somente, por meio, do trabalho no campo e a produção do lote um rendimento suficiente. Daí a necessidade de complementar sua renda com mão-de-obra assalariada ou trabalho temporário.

\section{A Criação do bicho da seda no São Bento}

O bicho-da-seda pode ser ainda classificado e identificado como de origem Japonesa, Chinesa, Europeia ou Indiana (KRISHNASWAMI et al., 1979). OKINO (1982) descreveu variações nas características do ovo (cor, forma), da lagarta (resistência, tamanho, cor, número de gerações/ano, número de ecdises) e do casulo (forma, tamanho, cor, rendimento) do bicho-da-seda, em função de sua origem.

Conforme Braslavsky et al. (1997), além do índice de sobrevivência da lagarta, do qual depende a produção do casulo, outras características quantitativas (teor de seda, conteúdo de fibra na casca sérica, comprimento, rendimento e uniformidade da fibra).

A sericicultura, produção de fios de seda através da criação do bicho-da-seda (Bombyx mori L.) tem a amoreira (Morus alba L.) como única fonte de alimento, de grande importância para o desenvolvimento da atividade. A qualidade e a quantidade de massa foliar produzida pela planta é alvo de inúmeras pesquisas, visando aumento da produção, aliada a qualidade do produto final, o fio de seda. Fatores como informação nutricional, teor de proteína das folhas de amoreira, digestibilidade e épocas de corte dos ramos são de suma importância para o entendimento das diferentes características apresentados nas cultivares.

O fornecimento de folhas ao bicho-da-seda com altos níveis de proteína e baixos teores de fibra proporciona melhor desenvolvimento das lagartas e maior produção de casulos de seda. Cerca de $100 \%$ da proteína do fio de seda produzido pelo bicho-da-seda, provém da folha de amoreira, de acordo com Hanada \& Watanabe (1986).

Aliado aos tratos culturais, o corte dos galhos de amoreira representam papel importante na manutenção das características químicas da planta, devendo o ramo ser coletando à aproximadamente cinco (5) $\mathrm{cm}$ do solo. Este procedimento deve ser feito no período da manhã, enquanto as folhas estão túrgidas, e no final de tarde quando a turgescência da folha volta ao normal. Para a conservação da qualidade dos ramos de amoreira, e para que as folhas apresentem condições ideais para 
consumo pelo bicho-da-seda, os ramos devem ser guardados em um deposito, para facilitar os tratos diários, sem prejudicar a produção de fios de seda pelo inseto (TAKAHASHI et al. 2009).

A criação do bicho-da-seda é uma alternativa de renda importante para o homem no campo. Muitos são os fatores: a possibilidade de obtenção de renda em ciclos mensais em áreas inferiores a 10,0 há; o baixo custo de produção; a racionalização da mão de obra familiar e a pequena dependência climática, com a maior parte do produto final (seda) sendo destinada ao mercado internacional. (TAKAHASHI et al. 2009).

A produção nacional vem decrescendo, saindo de 17 mil/ton em 1997 para 2, 709 mil/ton em 2013 (BALTAR; BALTAR, 2016). O Brasil ocupou a quarta posição, constituindo-se no único país ocidental entre os principais produtores sericícola. $\mathrm{O}$ maior produtor mundial é a China, com $76 \%$ do mercado, seguido da Índia, com 17,7\%, Vietnã com 2,7\% e Brasil, com 1,9\% (PORTO, 2014). Os dados da última Pesquisa Pecuária Municipal (PPM), do IBGE, mostram que, em 2017, o Brasil produziu cerca de 3 mil toneladas de casulos de bicho-da-seda, ficando em quinto lugar na produção mundial, atrás da China, Índia e Uzbequistão e Tailândia.

No estado de São Paulo, em 2002, havia um total de 147 assentamentos (ITESP, 2013), concentrados na região oeste, nas regiões administrativas de Presidente Prudente, Araçatuba e Bauru que, juntas, reúnem $73 \%$ dos lotes e $78 \%$ da área total de produção do bicho-da-seda (ANDRIETTA, 2013). Segundo dados do IBGE (2017), o Estado de São Paulo representa 12\% da produção nacional com 116 mil/Kg, o Paraná lidera a produção nacional com 83\%.

Segundo dados do IEA (2018) a produção de "bicho da seda" no município de Mirante do Paranapanema (região de Presidente Prudente) em 2016 era de 14.210,00 (Kg/ano) com uma área plantada de 31 há e em 2017 foi para 28.500,00 (kg/ano) com uma área plantada de 78 há , representando $12 \%$ da produção do estado.

Contudo, a monocultura extensiva de cana-de-açúcar, tem trazido consequências socioambientais para o sericicultor na região do Pontal do Paranapanema, em razão da prática da pulverização aérea nos canaviais, utilizadas pelas agroindústrias. Muitos são os prejuízos causados sericicultor, em especial no assentamento São Bento em Mirante do Paranapanema.

A aplicação dos agrotóxicos é comumente feita por meio da pulverização aérea, com o uso de aviões contratados pelas próprias empresas do setor 
sucroalcooleiro. A aplicação aérea dos agrotóxicos é procedimento que envolve sérios riscos ambientais, mormente se realizada em desacordo com todas as recomendações e exigências legais e regulamentares (PIRES E BARBATTO, 2016).

$E$ importante destacar que a sericicultura foi a atividade que mais sofreu os efeitos perversos dos agrotóxicos aplicados em culturas vizinhas, afetando a sustentabilidade das pequenas propriedades rurais na região do Pontal.

A prática da pulverização aérea nos canaviais, utilizadas pelas agroindústrias, tem provocado muitos prejuízos aos assentados que atuam na produção da sericicultura como a mortandade de bichos-da-seda na região.

Os produtores, assentados São Bento, tiveram suas amoreiras (alimentos para o bicho-da-seda) inutilizadas pela pulverização aérea de canaviais vizinhos aos assentamentos. Nesse caso, é relevante ressaltar que esse ato não impactou apenas a produção nos assentamentos, mas também destruiu o trabalho e a produção dos produtores assentados. Os produtores tiveram sua produção de sericicultura prejudicada e encerradas pela pulverização aérea dos agrotóxicos usados nos canaviais de agroindústrias das adjacências.

Essa é uma das faces perversas da expansão da monocultura da cana-deaçúcar para a região, em estudo os impactos e prejuízos trazidos a produtores assentados da sericicultura, juntamente com todos aqueles que porventura mantiverem alguma produção próxima aos canaviais são enormes, muitos tiveram que abandonar suas lavouras.

Através das informações obtidas, em entrevistas com os assentados do São bento III, podemos verificar com as suas falas a tradição da cultura da sericicultura na região: "agente sempre trabalho com bicho-da-seda, faz mais de 20 anos, mas depois que chegou a cana, nos bichos morreram". Outras ainda apontam a diminuição na renda: "agente tem perdeu muito, agora sem o dinheiro do bicho-daseda, agente não sabe o que fazer". Segundo ainda informações obtidas em entrevista, 60\% dos entrevistados não tem dinheiro para investir em outra atividade: "tenho muita vontade de começar já a plantar mas não tenho dinheiro". E os nossos filhos, não tem o que fazer aqui agora, tem que ir trabalhar em outro lugar", "Agente esta desamparado, a nossa vida acabou, não sei fazer outra coisa" E cerca de $25 \%$ dos reassentados ainda tem interesse no plantio de eucalipto. "Penso em começar a plantar eucalipto este ano ainda"; "tenho muita vontade de começar já a plantar"; "estou vendo que pedaço de terra eu vou começar a plantar" "estou conversando 
com minha mulher sobre quando realmente devemos começar a plantar"; "quero fazer as contas de novo".

Sobre a utilização de adubos e fertilizantes no cultivo ou renovação das pastagens, 18 (90\%) disseram utilizar, e, os principais produtos citados foram: "utilizo o esterco de gado mesmo, uso o supersimples, apenas jogo calcário, jogo a ureia, coloco granulado e uso o orgânico na horta (estrume animal)".

Nesse sentido, a pesquisa permitiu-nos apreender que o atual cenário no qual estão inseridas as lavouras de cana da região do Pontal do Paranapanema é de mais muitos desafios. Os projetos de expansão das lavouras estão cada vez mais direcionados para a ampliação das terras em que se cultivam os canaviais, fato que tem ocasionado gerados muitos impactos na região.

\section{Considerações Finais}

A expansão do agronegócio canavieiro na região do Pontal do Paranapanema tem acarretado uma série de impactos ambientais. Os impactos/consequências têm atingido tanto os municípios que possuem os canaviais e a mão de obra, quanto os que possuem as destilarias ou unidades canavieiras. Nesse sentido, o desenvolvimento da pesquisa de campo possibilitou-nos apreender a intensidade dos impactos negativos que a expansão da cana tem provocado nos municípios da região, quer aqueles que abrigam as unidades canavieiras, quer os que abrigam somente os canaviais.

De modo geral, percebe-se que os prejuízos existem, e os municípios, têm consciência, porém, não se posicionam de maneira contrária as unidades produtores, sobretudo aqueles que acomodam as grandes unidades. Os problemas gerados são vários: os desgastes devido ao tráfego intenso de caminhões pesados, os prejuízos nas pequenas propriedades com a diminuição da produção agrícola ou até a perda total da produção, como no caso da sericicultura, prejudicada pela da pulverização aérea - como aconteceu em Mirante do Paranapanema, com os produtores assentados do São Bento.

Por fim, evidenciamos que é de suma importância estudar e entender as alterações na dinâmica da produção no campo, sobretudo, os processos de agroindustriais que criam novos movimentos e novos territórios de articulação, essenciais para entender os problemas ambientais atuais. 


\section{REFERENCIAS}

ANTUNIASSI, U. R. Tecnologia de aplicação de defensivos na cultura da soja. Boletim de Pesquisa de Soja Fundação Mato Grosso, Rondonópolis, v. 11, p. 199-216, 2007.

ANDRIETTA, A.J. Reforma agrária no estado de São Paulo: após duas décadas, sucesso ou fracasso? Instituto de Economia Agrícola, São Paulo, p.1-5, 2013.

BALTAR, Claudia S.; BALTAR, Ronaldo. Caminhos da seda no Paraná: a convergência de diferentes processos migratórios na expansão da sericicultura de São Paulo até o Vale da Seda (PR) In. VII Congreso de la Asociación Latinoamericana de Población e XX Encontro Nacional de Estudos Populacionais,

ABEP, realizado em Foz de Iguaçu-PR - Brasil, de 17 a 22 de outubro de 2016. http://www.abep.org.br/xxencontro/files/paper/1176-1047.pdf

BRASIL. Ministério do Desenvolvimento Agrário. A agricultura familiar no Brasil. Brasília, 1998.

BRASIL. Senado Federal. Projeto de Lei do Senado $n^{\circ}$ 541, de 2015. https://www25.senado.leg.br/web/atividade/materias/-/materia/122747/pdf

BERGAMASCO, S. M. P. P; NORDER, L. A. C.; et.all. A diversidade dos impactos locais e regionais dos assentamentos rurais em São Paulo. In: MEDEIROS, L. S. de.; LEITE, S. (orgs.) Assentamentos Rurais: mudança social e dinâmica regional. São Paulo: Mauad, 2004. p.97-140.

BEZERRA, J. P. P. Planejamento Ambiental da bacia Hidrográfica do Ribeirão Santo Antônio - Mirante do Paranapanema (SP). 2011. Dissertação (Mestrado) - Programa de Pós-Graduação em Geografia, Universidade Estadual Paulista, Presidente Prudente-SP.

BONINI, J. V. Tecnologia de aplicação de fungicidas na cultura da soja. 2003. $63 \mathrm{f}$.

Dissertação (Mestrado em Agronomia)-Universidade Federal de Santa Maria, Santa Maria, 2003.

BRASLAVSKY, M.E. et al. Working out base silkworm selection programs in Ukraine. In: CONGRESSO DA COMISSÃO SERICÍCOLA INTERNACIONAL, 17., 1997, Londrina. Anais.. Londrina : Governo do Estado do Paraná, 1997. Seção 2, p.147.

CAMARGO, A. M. M. P. de et al. Dinâmica e tendência da expansão da cana-de-açúcar sobre as demais atividades agropecuárias, Estado de São Paulo, 2001-2006. nformações Econômicas, São Paulo, v. 38, n. 3, p. 47-66, mar.2008.

CATI Projeto lupa: censo agropecuário 1996. Campinas. CATI. 1997. Disponível em: http://www.cati.sp.gov.br/serviços/lupa/estado.htm.. Acesso em: 20 de outubro de 2003.

COELHO, S. T.; LORA, B. A.; MONTEIRO, M. B. C. A. A expansão da cultura canavieira no Estado de São Paulo. In: CONGRESSO BRASILEIRO DE PLANEJAMENTO ENERGÉTICO - CBPE, 6., 2008, Salvador (BA). Anais... Salvador: CBPE, 2008.

FERREIRA JÚNIOR, Antonio Carlos; HESPANHOL, Antonio Nivaldo. A cana-de-açúcar nos assentamentos rurais Santa Terezinha da Alcídia da Gata no município de Teodoro Sampaio - SP. In: ENCONTRO DE GRUPOS DE PESQUISA, 2., 20-22 de junho de 2006, Uberlândia - MG. Anais.. 
Disponível em:<http://w3.ufsm.br/engrup/iiengrup/pdf/t02.pdf> Acesso em: 08 jan. 2017

FRANCISCO, F.C. Análise Ambiental e Consequências do desmatamento no Município de Presidente Prudente no Período de 1917 a 1986. Rio Claro, Instituto de Geociências e Ciências Exatas, 1989. il. Dissertação (Biogeografia).

FERNANDES, Bernardo Mançano. Espacialização e territorialização da luta pela terra: a formação do MST -Movimento dos Trabalhadores Rurais Sem Terra no Estado de São Paulo. 218 f. Dissertação (Mestrado) -Universidade de São Paulo, Faculdade de Filosofia, Letras e Ciências Humanas. São Paulo. 1994

FUNDAÇÃO ITESP. Fundação Itesp: sua história e realizações. Evolução das políticas agrária e fundiária no Estado de São Paulo. São Paulo: ITESP, 2013.

GONÇALVES, D. B.; FERRAZ, J. M. G.; SZMRECSÁNYI, T. Agroindústria e meio ambiente. In: ALVES, F. et al Org.). Certificação socioambiental para a Agricultura: desafios para o setor sucroalcooleiro. Piracicaba (SP): Imaflora; São Carlos (SP): Edufscar, 2008

HESPANHOL, R.A.M. Implantação de Assentamentos Rurais e as Alterações no Município de Euclides da Cunha Paulista. in: ENCONTRO NACIONAL DE GEÓGRAFOS. Anais. 10. Recife. 1996. Vol 1 p.550-551.

ITESP. INSTITUTO DE TERRAS DO ESTADO DE SÃO PAULO. Retrato da Terra-1997Perfil Socioeconômico dos Assentamentos do Estado de São Paulo, 2013.

ITESP. INSTITUTO DE TERRAS DO ESTADO DE SÃO PAULO. Disponível em http:// www.institutodeterrasdesãopaulo.gov.br acesso 05/Nov 2006

IBGE, Instituto Brasileiro de Geografia e Estatística - Banco de dados e Anuário Estatístico, 2006

IBGE, Instituto Brasileiro de Geografia e Estatística- Pesquisa da Pecuária Municipal - PPM, 2017

https://www.ibge.gov.br/estatisticas-novoportal/economicas/agricultura-e-pecuaria/9107

IEA- Instituto de Economia Agrícola. Secretaria de Agricultura e Abastecimento de São Paulo, 2018 http://ciagri.iea.sp.gov.br

LANGOWSKI, E. Queima da cana: uma prática usada e abusada. Cianorte, maio de 2007. Disponível em: Acesso em: 23/07/2007

LANZOTTI, R.L. Uma Análise energética do setor sucroalcooleiro. Disponível em: <http://biblioteca.universia.net/html_bura/ficha/params/id/3965414.html>. 10/09/2007

LEITE, J. F. A Ocupação do Pontal do Paranapanema. Presidente Prudente. Instituto de Planejamento e Estudos Ambientais, 1981. 256p. il. Tese (Livre Docência em Geog. Reg.).

MAROCHI, A. I.; SCHMIDT, W. Plantio direto na palha: tecnologia de aplicação de Scorpion no sistema. Castro: Fundação ABC/ Dow Agrosciences, 1996. 43 p.

KRISHNASWAMI, S. et al. Sericulture manual 2-silkworm rearing. Rome : Food and Agriculture Organization of the United Nations, 1979 
HANADA, Y.; WATANABE, J.K. Manual de criação do bicho-da-seda. Curitiba: Cocamar, 1986.

OMS. Organização Mundial da Saúde. Trabalhando juntos pela saúde / Organização Mundial da Saúde. - Brasília : Ministério da Saúde, 2007. 210 p. - (Série B. Textos Básicos de Saúde).

OKINO, I. Manual de sericicultura. Bauru: DIRA/CATI, 1982. 80p

PASSOS, M.M. dos O Pontal do Paranapanema: um estudo de geografia física global. 1988. Tese (Doutorado) - São Paulo: FFLCH-Universidade de São Paulo, 1988.

PIRES, Gabriel L. S. e BARBATTO, Silvio M. Abordagem jurídica da inadequada aplicação de agrotóxico por aviões na atividade sucroalcooleira: experiência do GAEMA. Revista Jurídica ESMP-SP, v.9, 2016: 119-142 http://www.esmp.sp.gov.br/revista esmp/index.php/RJESMPSP/article/viewFile/296/157

PORTO, A.J. Sericicultura no estado de São Paulo. Boletim Indústr. Anim., Nova Odessa, volume 71, no.3, p.291-302, 2014. (Revisão bibliográfica).

QUEIROZ, Maria Isaura Pereira de, Variações sobre a técnica do gravador no registro da informação viva. Biblioteca básica de Ciências Sociais. Série 2. Textos, v.7.1991.

RAMOS, H. H. Tecnologia de aplicação de agrotóxicos. Fitopatologia Brasileira, Brasília, DF, v. 25 , p. $275-283,2000$. Suplemento.

SCHRÖDER, E. P. Avaliação de deriva e deposição de pulverizações aeroagrícolas na região sul do Rio Grande do Sul. Dissertação de mestrado em Agronomia. Pelotas: UFPel, 1996. $68 p$

SOUZA, V. F. Acampar, assentar e organizar: relações sociais constitutivas de capital social em assentamentos rurais do Pontal do Paranapanema. 2006. Tese (Doutorado em Engenharia Agrícola) - Universidade Estadual de Campinas

SOUZA, L. 2007. Localização e perfil do Pontal do Paranapanema. Disponível em: $<$ http://www.skyscrapercity.com/showthread.php?t=1593100>. Acesso em: 24 jan. 2015

SOBREIRO FILHO, José. LUTA PELA TERRA NO PONTAL DO PARANAPANEMA: HISTÓRIA E ATUALIDADE. Revista GEOGRAFIA em Questão. V.05, N. 01, 2012 pág. 83-114.

https://www.researchgate.net/publication/280050741_A_LUTA_PELA_TERRA_NO_PONTA L_DO_PARANAPANEMA_HISTORIA_E_ATUALIDADE [accessed May 14 2018].

SILVA, J.C. Cresce presença do eucalipto no Brasil. Revista da Madeira, n. 92, 2005

TAKAHASHI, R.; TAKAHASHI, M.K.; TAKAHASHI, L.S. Sericicultura: uma promissora exploração agropecuária. 1. ed. Jaboticabal: Funep, 2009

TSUNECHIRO, A.; COELHO, P.J.; CASER, D.V.; AMARAL, A.M.P.; MARTINS, V.A.; VITOUSEK et al. Human domination of earth's ecosystems. Science. V.227, 25 July, 1997. p.494-499. 


\section{NOTAS DE AUTOR}

\section{CONTRIBUIÇÃO DE AUTORIA}

Alba Regina Azevedo Arana - Concepção. Coleta de dados, Análise de dados, Elaboração do manuscrito, revisão e aprovação da versão final do trabalho

Maíra Rodrigues Uliana - Concepção e elaboração do manuscrito.Participação ativa da discussão dos

resultados; Revisão e aprovação da versão final do trabalho.

Cintia Ramos Lopes Evangelista - Concepção e elaboração do manuscrito. Coleta de dados Participação ativa da discussão dos resultados; Revisão e aprovação da versão final do trabalho.

\section{FINANCIAMENTO}

PPG/PEIC -Universidade do Oeste Paulista; Programa em meio Ambiente e Desenvolvimento Regional.

\section{CONSENTIMENTO DE USO DE IMAGEM}

Não se aplica

\section{APROVAÇÃO DE COMITÊ DE ÉTICA EM PESQUISA}

Aprovação do comitê de ética, CAAE: 21905013.8.0000.5515.

\section{CONFLITO DE INTERESSES}

Não há conflitos de interesse

\section{LICENÇA DE USO}

Este artigo está licenciado sob a Licença Creative Commons CC-BY. Com essa licença você pode compartilhar, adaptar, criar para qualquer fim, desde que atribua a autoria da obra.

\section{HISTÓRICO}

Recebido em: 24-10-2018

Aprovado em: 03-02-2019 